- Continuing Education \& Training

\title{
Mentorship in Health Disciplines
}

YOUSRIA ELSAYED, PHD. CAIRO UNIVERSITY, 2020

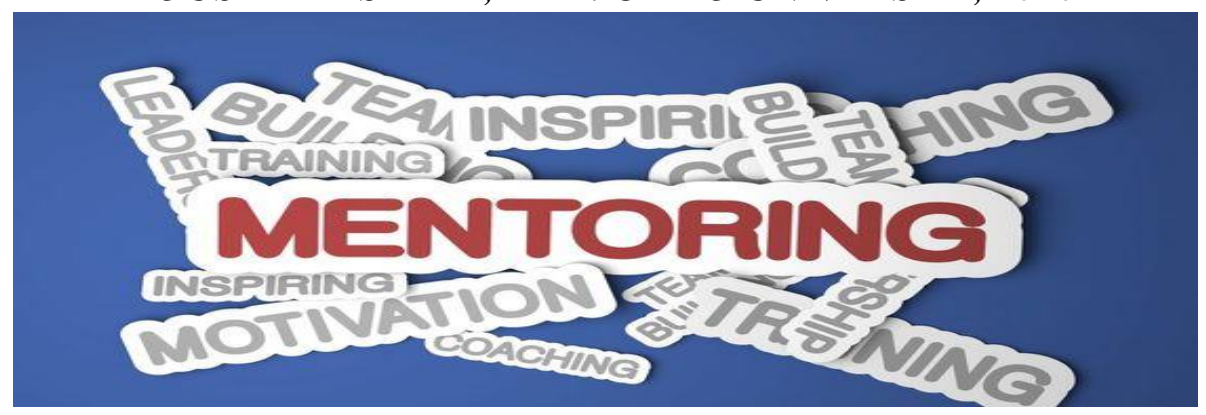

\section{Introduction:}

Mentorship is a broad concept, which is generally related to personal and professional development in the long term. Depending on the context, this relationship can be formal or informal, and is based on the principles of reciprocity, mutual trust and respect. Meanwhile, the mentor relationship primarily aims to identify and support the potentials in the mentee.

\section{Why Mentorship?}

- Clinical Mentorship:

According to WHO (2005), clinical mentorship is a system of practical training and consultation that fosters professional development to provide highquality clinical care outcomes. In clinical settings, mentorship sets the foundation for a positive learning environment. Meanwhile, mentoring is considered an integral part of continuing education, as well as an important component of the continuum of education, in order to support health care providers. However, it starts at the point where the initial training ends (Henderson, Briggs, Schoonbeek \& Paterson, 2011).

Inter-professional learning aims at facilitating and lessens the burden of individualized student's supervision and evaluation. Also, besides their specificdiscipline supervision, other disciplines will act as student's inter-professional 
mentor. Yet, both mentors can actively work collaboratively to meet the student' Learning objectives.

The mentor-mentee relationship includes four stages, which includes preparation, negotiation: enabling and closure. Therefore, mentors need to be equipped with experience and clinical competencies, supported with strong teaching skills. They provide mentees with learning opportunities that increase satisfaction, reduce dependence and provide a sense of belonging within the workplace. Moreover, they initiate feelings of self-worth and acceptance as a valued team member (Myall, Levett-Jones and Lathlean, 2008).

According to the recommendations of "The Nursing and Midwifery Council" (NMC, 2018), new developed standards for students' supervision and assessment will be implemented, starting from the year 2020, where the following new features of mentorship will be considered:

1. A change in the mentor's role as rationally used.

2. Less time is needed for mentor-student contact.

3. Learning and supporting students will be among the responsibility of every

Registered practitioner in the clinical setting.

4. Non-nursing professionals will participate in the students' supervision.

5. Registered practitioners supervising/assessing students should be professionally prepared and keep their skills up-to date.

6. The mentorship concept as a shared educational approach for students in the clinical practice will encourage the inter-professionals exchange between students and staff from other disciplines (Alberta Interprofessional mentoring guide (2011).

- Academic Mentorship:

Traditionally, mentorship has been seen as a long-term mutually beneficial relationship between junior and senior in the academic education. Recent changes produced alternative forms of mentoring such as collegial, facilitated peer, functional, and online, as well as distance mentoring (Brownie, 2019).

Nowadays, there is an increased demand for providing mentorship to academics females, particularly in faculties of health, where a number of 
disciplines such as nursing, psychology, physiotherapy, pharmacy, and occupational therapy are predominantly females profession (Brownie, 2019).

\section{Benefits, Barriers and Enablers of Academic Mentorship:}

Benefits: Entail career and personal development, academic craftsmanship, psychosocial support and job satisfaction. However, providing female health academics with experienced, well-connected mentors with common interests, and committed to update their career, is considered an investment in optimizing potentials, promoting supportive work environments and increasing productivity, as well as retention.

Barriers: Associated with personal and relational dynamics, women often find it difficult and time-consuming to find a suitable mentor, who can share their similar interests. Additionally, some men find limitations in criticizing women. The lack of, or inadequate mentoring for female health academics led to decreased job satisfaction, limited career development and reduced productivity.

Enablers: Academic mentoring is successfully achieved by the availability of mentor, expertise, and supportive relationships, which are mutuality responsive to shifting needs.

The provision of effective mentoring for female health academics is dependent on the organizational environment, specifically workplace structures and relationships. Also, it represents a long-term investment that can benefit academics and their mentors. Moreover, mentorship assists the higher education institutions to address faculty shortage, increase retention and productivity, advance female academics 'careers, as well as build their mentoring capacity.

\section{Characteristics of good qualified mentor comprise:}

- The desire to guide and advice.

- Consistency, accessibility and continued support.

- Emotional intelligence: the ability to measure one's emotions and sensitive to the emotions of their mentee.

- Good interpersonal communication skills and the ability to share others knowledge and experiences. 
- Tolerance and the ability to set aside personal bias and be nonjudgmental.

- Good teaching ability, constructive feedback, fosters critical thinking and provide an appropriate level of challenging learning opportunities.

- Positive attitude, passion, friendliness, enthusiasm and professional motivation.

- Ability to value and empower the mentee as a learner, team member and consequently display mutual respect and trust.

- Finally, have the ability to set realistic goals and be the source of various learning opportunities.

\section{How to give an effective feedback?}

\section{The CORBS acronym for guiding feedback}

- Clear: Clarity is essential. Ensure you know what feedback you want to deliver before you provide it. Being vague increases the recipients' anxiety and potentially convey mixed messages and damage the mentor relationship.

- Own: 'Own' the feedback you give never give 'second-hand' feedback. Start your feedback with 'I' statements as this assist in providing specific feedback rather than leaving the recipients guessing what you actually mean.

- Regular: Always aim to provide feedback as close to the event as possible. This enables the learner to establish goals for improving practice in a timely manner as required. If the feedback you want to deliver is positive in nature, refrain from saying "Well done today". Be specific about what they did well and always aim to provide positive feedback at the end of each day; this boosts their confidence and selfesteem.

- Balanced: It is good to balance negative and positive feedback; if the feedback you give to an individual is either positive or negative, this probably means your view is distorted in some way. This does not mean 
that each piece of critical feedback must always be accompanied by something positive, but rather a balance should be created over time.

- Specific: It is difficult to learn from feedback that is generalized. This applies to comments, positive and negative feedback.

\section{Effective \\ Supportive and accepting \\ Sensitive and considerate \\ Owned and specific \\ Regular and thoughtful \\ Active engagement \\ Authentic and balanced \\ Open \\ Reflective and responsive}

\section{Mentor's Feedback}

$$
\text { Versus }
$$

\section{- Conclusion:}

Mentors play a vital role in the education of future healthcare professionals and in enlightening the way in which they approach this role, which significantly impacts the quality of the mentee's learning experience. Ultimately, today's mentees are tomorrow's colleagues. It is important for everyone that the mentor-mentee relationship is maintained correctly. The aim of this presentation is to enable us to reflect on our current approaches to provide feedback to mentees and identify areas that may require change.

NB This integrative literature review synthesizes the primary research evidence on mentoring female health academics published from 2000 to 2018. It is implemented in order to identify the benefits, enablers and barriers to mentoring women. The need for this review is underpinned by the magnitude of change in higher education, the high number of women in health disciplines, the limited progress in advancing women's academic careers, the escalating role expectations, and the faculty shortage sand staff turnover. 


\section{References:}

1- WHO: Planning Consultation on Clinical Mentoring: Approaches and Tools to Support Scaling-up of Antiretroviral Therapy and HIV Care in Low- resource Settings. , Geneva, Switzerland, 7-8 March 2005 http://www.who.int/hiv/pub/guidelines/clinicalmentoring.pdf

2- Henderson, Briggs, Schoonbeek \& Paterson: Baccalaureate nursing students' perceptions of learning and supervision in the clinical environment, Nursing and Health Sciences (2015), 17, 236-242

https://onlinelibrary.wiley.com/doi/pdf/10.1111/nhs.12174

3- NMC : Realizing professionalism: Standards for education and training,Part 2: Standards for student supervision and assessment, Published 17 May 2018 https://www.nmc.org.uk/supporting-information-on-standards-for-student-supervisionand-assessment/

4- Brownie: Benefits, barriers and enablers of mentoring female health academics: An integrative review, PLoS Onev.14(4); 2019P. Published online 2019 Apr 18

https://www.ncbi.nlm.nih.gov/pmc/articles.

5- Hawkins, Peter; Smith, Nick: Coaching, Mentoring and Organization Consultancy: Supervision, Skills and Development: McGraw-Hill Companies Inc. January 1, 2007

https://www.ualberta.ca/health-sciences-education-research/standardized-patients/ 
Figure: 1. Best Practices in Academic Mentoring: A Model for Excellence. $4^{\text {th }}$ Cohort, NLN/Johnson \& Johnson Faculty Leadership and Mentoring Program.

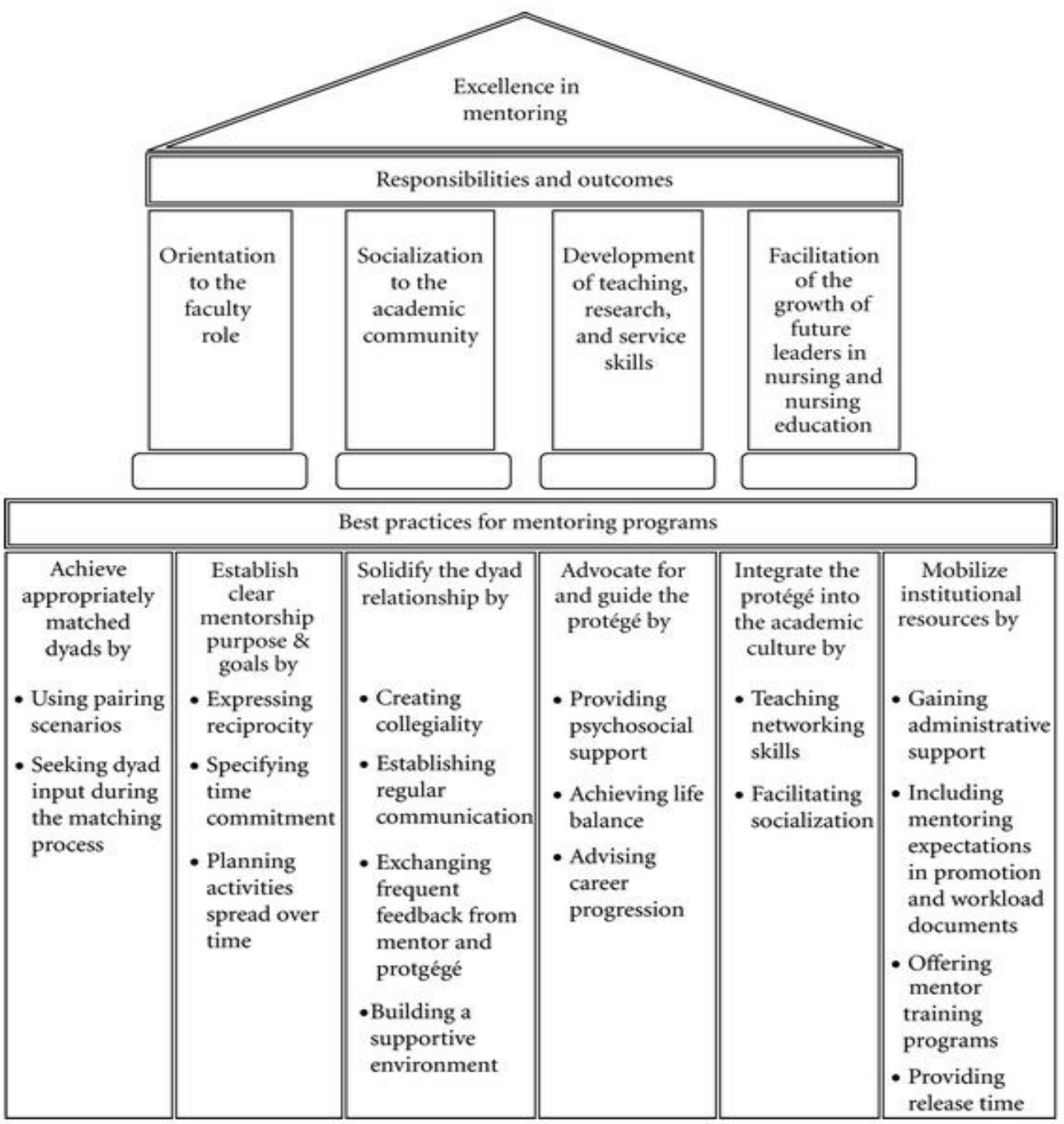

YOUSRIA ELSAYED, PHD 